\title{
An Analysis of Sports Agent Regulation in Intercollegiate Athletics: A Call for Cooperation
}

\author{
Ross Viltz, Chad Seifried, and Jeremy Foreman
}

\begin{abstract}
The purpose of this article is to review the current environment associated with agents, student-athletes and the other parties involved with the organization and management of intercollegiate sport and to discuss how these groups can better work together at Division I Football Bowl Subdivision (FBS) institutions. Within, a total of $29(23.2 \%)$ of the 125 Division-1 FBS universities responded to our request to provide institutional literature on their agent policies and Agent Days. Results from this request and analysis of documents show some effort to educate student-athletes about sport agents and to create an ethical environment but more could be done. Next, this work sought to review the realities/outcomes of unethical agent and student-athlete relationships and explain the policies and practices of the NCAA as well as federal and state laws regarding agent and student-athlete interaction. Finally, this work offers a variety of suggestions/recommendations to better protect student-athletes and institutions.
\end{abstract}

According to the National Football League Players Association (NFLPA; 2006), there are more than 700 registered agents allowed to work for the National Football League (NFL). Bechta (2009) explained that after the final roster cuts nearly 400 of these agents will have no clients on an NFL roster and therefore no income to pay off their large expenses. The need to acquire clientele in this industry has prompted the recruitment and pursuit of potential clients as early as possible (i.e., at the intercollegiate level). Further, the growth of agent competition for prospective clients has led toward more unethical and illegal contact and behaviors within intercollegiate athletes (Couch, 2000).

Couch (2000) proposed the phenomena involving the creation and expansion of the sports agent and student-athlete relationship stands as one of the major issues current and future intercollegiate program directors need to address. For example, inexperience and immaturity paired with the complexity of being a highly sought after collegiate athlete often leads to a relationship that is unequal and as a result not completely beneficial to the student-athlete. Surrounding pressures from family members, coaches, and the media also contribute to unexpected and/or poor decisions that may not only affect the future opportunities of the student-athlete but

Viltz is with the Tiger Athletic Foundation, Louisiana State University, Baton Rouge, LA. Seifried (cseifried@1su.edu) and Foreman are with the School of Kinesiology, Louisiana State University, Baton Rouge, LA. 
his or her current situation (Seifried, 2009). For a majority of the student-athletes, the lack of knowledge, preparation, and an abundance of uneducated mentors and blind trust in an agent has led to the current state of the sports agency industry being perceived as one which produces and unethical conduct by many and the overestimate of student-athlete worth or ability (Couch, 2000; Evans, 2010; "National Collegiate," 2011, 2010a; "Schools Push," 2013).

Within the past few years, several meetings and initiatives started by the National Collegiate Athletic Association (NCAA) served to identify improper agent conduct or behavior as a major area of concern and one that needs vigilant regulation and attention (Isch, 2010, "National Collegiate," 2011; Newman-Baker, 2010; Newman-Baker \& Smith, 2011; "Schools Push," 2013; "Solving the Problem," 2010; "Statement," 2010). However, despite this recognition the NCAA is promoted as increasingly obsolete and/or nonattentive to this issue because it does not engage in aggressive agent supervisory activities, lacks accountability, creates unrealistic policies, and provides only indirect enforcement of agent-related policies (Davis, 2006; "Schools Push,” 2013). Interestingly, Fowler (2013) claimed the NCAA supports this statement through suggestions that they are not working on any proposals related to sports agents. Further validation can also be seen from the 2014 NCAA Convention because there was no mention of agents anywhere on the agenda or program ("Convention," n.d.). Collectively, such inactivity and lack of interest has led some to suggest the work of unscrupulous agents are no longer a priority of the NCAA (Fowler, 2013; Solomon, 2013) and that agent supervision and/or regulation is still a significant problem (Cassidy, 2013; Pogge \& Agnone, 2013; "Saban Compares," 2010; "Schools Push," 2013; "Report," 2010). Moreover, some argue (e.g., Cassidy, 2013; Nocera, 2013) state and federal law enforcement could possibly do more to protect student-athletes and that the rules established by the NCAA strongly influences agents, student-athletes, and universities to secure positions as either victims or outlaws.

The purpose of this article is to review the current environment associated with agents, student-athletes and the other parties involved with the organization and management of intercollegiate sport and to discuss how these groups can better work together. The duty to investigate and prevent the aforementioned types of violations is tremendous and potentially overwhelming ("National Collegiate," 2010a). Thus, without guidance, student-athletes and their respected universities may continue to suffer severe punishments and negative outcomes when improper relationships are established with sport agents. Another goal of this work is to better understand the current level of attention provided to student-athletes and agent contact at Division I Football Bowl Subdivision (FBS) institutions through a survey and review of institutional literature with respect to agent policies and Agent Days. Agent Days are organized opportunities supported by universities to inform student-athletes about their future in a professional sports industry and to meet agents in the university controlled setting (Ohio State, 2009). Division I FBS was chosen as the context for this study because these institutions support the highest percentage of professional athletes across all sports ("2014 MLS", n.d.; Fowler, 2013; "MLB Draft", n.d.; "NFL Draft", n.d.; "Probability of Competing", 2013; "Year-By-Year", n.d.).

To establish additional justification and significance regarding this topic, additional sections of this paper communicate important variables that influence 
student-athlete and agent interactions. For example, this research effort reviews the dramatic differences in environments for student-athletes and universities compared with those of sports agents. Next, policies and practices of the NCAA as well as federal and state laws regarding agent and student-athlete interaction are examined. Within, a review of laws such as the Sports Agent Responsibility and Trust Act (SPARTA) and the Uniform Athlete Agent Act (UAAA) as well as other examples of current state regulations explains the tendencies of this industry and how these regulations manipulated agent interaction and their approaches with student-athletes in the NCAA. The final section will discuss the potential opportunities to address agent conduct and issues through the pursuit of the aforementioned information and service activities (i.e., Agent Days) provided by institutions. Finally, this work makes recommendations such as including more cooperative educational opportunities for student-athletes, proposing a reconstruction of agent regulations, calling for a potential creation of a national governing association for agents, and asking for a protection policy to be developed for whistle blowing student-athletes and universities.

\section{Literature Review}

A survey conducted by ESPN questioned 20 Division I college basketball players about issues in collegiate sports. The group collectively agreed that of all the problems associated with amateur athletics, agents were the most significant (O'Neil, 2010). Appropriately, one of the most visible and controversial policies of the NCAA is the regulation of agent and student-athlete interaction (Isch, 2010; "National Collegiate," 2010b, 2010c; Newman-Baker \& Smith, 2011; "Statement," 2010). As an example, according to the NCAA (2010b), benefits, transportation, and any type of agreement that leads to representation of a student-athlete by an agent is not allowed. Activities or agreements between a student-athlete and agent for the purpose of marketing their ability before the completion of their eligibility is also prohibited ("National Collegiate," 2010b). Benign neglect shown by influential parties associated with student-athletes (e.g., coaches, friends, and family) also highlights the difficult environment that the NCAA, student-athletes and universities must manage because these individuals would likely deny acknowledgment of any potential wrongdoings and may influence early or ill-conceived decision for their own self-interests.

These pressures from agent contact are problematic to student-athletes because the consequences they face are those that agents frequently do not share. For example, agents traditionally received little or no punishment for their involvement other than the potential loss of a client and negative publicity (Couch, 2000; Fluhr, 1999). Student-athletes risk suspension or expulsion from their sport and collegiate career as well as jeopardizing the reputation of their institution and their own potential as a marketable commodity (Riepenhoff \& Wagner, 2010). For example, Albert Minnis, a baseball pitcher for Wichita State University received a 30-game suspension from the NCAA in 2011 for utilizing the services of an agent or advisor who contacted the Atlanta Braves before the 2010 Major League Baseball (MLB) draft. In violation of NCAA Bylaw 12.3.1, the conversations between Minnis' agent/ advisor centered on his past and future pitching performances ("Minnis Ineligible," 
2011). In another example, the University of Southern California (USC) was placed on a two-year postseason ban by the NCAA when a former Heisman Trophy winner (i.e., Reggie Bush) accepted improper benefits related to agent conduct. According to the NCAA Infractions Committee, Bush and other parties associated with Bush, received cash, account deposits, cost-free transportation, lodging, hotel rooms, limousine services and furniture. The case ruling also included a list of over 20 penalties including public embarrassment, probation, postseason ban, removal of team victories, reduction in recruiting capabilities of coaching staff, various fines and a detailed prohibition of noninstitutional individuals in team areas ("National Collegiate," 2010a).

Finally, at the University of North Carolina (UNC) at Chapel Hill, studentathletes Greg Little and Robert Quinn were declared permanently ineligible by the NCAA in October 2010 for violation of the agent benefits provision in bylaw 12.3.1 because each received benefits approximated at $\$ 4,952$ and $\$ 5,642$ respectively ("National Collegiate," 2010d). Little's benefits included diamond earnings, travel accommodations to the Bahamas, Washington, D.C., and Miami while Quinn was found to have accepted two black diamond studded watches, diamond earrings, and travel accommodations to Miami. The UNC football team, preseason ranked in the top 25 by both the USA Today Coaches Poll and Associated Press Poll, finished the season disappointingly at 8-5 without Little, Quinn, and other members of the football team accused of similar violations. The scandal at UNC motivated Paul Pogge, an associate athletic director at UNC, to coauthor a nine page memorandum with recommendations for amending the Uniform Athlete Agents Act (UAAA) which was signed by representatives from 65 other universities (Leung 2013; Pogge \& Agnone, 2013; "School Officials," 2013).

Since leaving UNC, Quinn has failed to avoid controversy involving relationships with unscrupulous agents. Quinn and his agents were sued by Carl Carey, Quinn's former agent, for allegedly fraudulently extracting nearly $\$ 300,000$ from Carey (Carter, 2010; Champion Pro Consulting Group, Inc. v. Impact Sports Football, LLC, 2013; Getlin, 2012). Carey described how both sides of the relationship between student-athletes and sports agents are becoming increasingly corrupt (Getlin, 2012). Once a student-athlete signs a contract with an unethical agent, the agent does not become an ethical agent. In fact, the opposite may be true since the sports agent industry continues to get more unscrupulous over time (Fowler, 2013; Getlin, 2012; Solomon, 2013).

Student-athletes face the harsh reality that they could be taken advantage of by agents and not prepared for their life after professional sports (Florio, 2012; Getlin, 2012; Getlin \& Cole, 2013; Mullen, 2010). As an example, research cited by Rand Getlin, founder and head of Synrgy Sports Consulting, showed that $78 \%$ of all NFL players exhausted their earned finances within two years of leaving the professional ranks (Forde, 2010). Likely the complexity of the relationship and various jobs duties assumed by the agent allow them the opportunity to gain control over athlete finances to produce this outcome. Another result of the agent and studentathlete interaction might be the rise of threats or actual physical violence. As an example, in the United States v. Walters (1993), agents Norby Walters and Lloyd Bloom established contracts with 58 undergraduate football student-athletes before the completion of their eligibility. Walters and Bloom supplied their clients with lavish gifts and benefits such cars, money, airline tickets, and clothing to establish 
their relationship or to receive a percentage of their income when they became pro athletes. Those that did not follow through with their commitment to Walters and Bloom's company World Sports and Entertainment, Inc. (WSE) or looked to sign with another agency were threatened with physical harm. Rival agencies also allegedly received threats to stay away from prospective WSE clients and on one occasion WSE was connected to an assault on an employee for the Zucker Sports Management Group, following the signing of three former WSE clients. Overall, this information highlights why many public officials and university representatives have stepped forward to advocate for increased protection from unscrupulous sports agents to be provided for student-athletes (Leung, 2013; Pogge \& Agnone, 2013; "School Officials," 2013; "Schools Push,” 2013).

\section{The Reality of Sport Agents and Their Industry}

Competition from unqualified agents and against large agencies is regularly recognized as a major contributor to the unethical and illegal reality that many agents produce (Newman-Baker \& Smith, 2011; "Statement," 2010; Neiman, 2007). Specifically, there is an increased likelihood that many of the student-athletes with professional potential will choose to sign with larger, well known agencies. For example, the National Basketball Association (NBA) showed the 12 largest registered sport agencies represented over $61 \%$ of the league's players recently (Deveney, 2006).

Besides the unbalanced nature of the industry, another area that affects agent competition is the restriction players' associations place on agent compensation. For example, $3 \%$ of any NFL player's contract is the largest amount of compensation an agent may receive ("National Football," 2006). This percentage is lower than any other of the four large professional sports agent compensation regulations (Dohrmann, 2010). These regulations prevent agents and agencies from receiving larger committable guarantees from players and likely prompt the continued search for more clients and to start as early as possible because agents and agencies receive a very constricted portion of contracted incomes.

Another area of amateur athletics that affects the agent industry and their conduct involves the potential dependency student-athletes possess with head coaches, assistant coaches and other staff members. Student-athletes spend incredible amounts of time and develop large amounts of trust with members of their school's coaching staff. These coaches, often former players, are very influential in the decisions of their players' professional career choices. Thus, agents frequently approach and befriend coaches to influence potential client career choices ("National Collegiate," 2010b, 2010c; Newman-Baker \& Smith, 2011; "Solving," 2010; "Statement," 2010). Agents also face the possibility of being approached by members of a coaching staff who promise the signing of student-athletes for compensation ("National Collegiate," 2010c, 2010d; Newman-Baker \& Smith, 2011; "Statement," 2010). In the above example related to the University of North Carolina football team, Assistant Coach John Blake was accused of setting up the UNC football players with agent Gary Wichard who he had known for roughly 25 years (Robinson \& Fischer, 2010). Other similar reports also identified, "Agents paying position coaches to recruit student-athletes" and "assistant coaches participating in the agent selection process" (Forde, 2010, para. 29). 
Rick Smith, President and General Counsel of Priority Sports and Entertainment, further acknowledged that may of his peers are willing to work with another group of people called 'runners' to gain a competitive advantage when trying to land a prospect (Newman-Baker \& Smith, 2011). A rather unscrupulous behavior common in the sport agent business, 'runners' or intermediaries function as individuals who befriend student-athletes and seek to sell their services to the highest bidder among agencies/agents (Couch, 2000; Newman-Baker \& Smith, 2011; "National Collegiate," 2010c). In this scenario, runners provide studentathletes with extra benefits like money and cars to help them at their institution in exchange opportunity to sell their services to another agent (Nocera, 2013). In the 2013 NCAA football season, five Southeastern Conference (SEC) student-athletes were reported to have received over $\$ 45,000$ from a 'runner' named Luther Davis who was allegedly funneling these funds from sports agents ("Alabama's D.J.," 2013; Solomon, 2013). Interestingly, the NCAA has previously presented on this issue and the others recognized in this section and recommended the creation of both education and special investigative units (Isch, 2010; Newman-Baker, 2010; "National Collegiate Athletic Association," 2010a; "NCAA Studying," 2010). Still, the literature indicates they continually meet with little action and effectiveness to evoke change.

\section{The International Market for Athletes}

Beyond sport in the United States, the international professional sports world has become a major factor in the amateur status of student-athletes in the NCAA (Newman-Baker \& Smith, 2011). According to Scott Johnson, associate director of academic certification at the NCAA Eligibility Center, many of the challenges universities face are caused by the differences in higher education between the United States and the almost 200 countries the NCAA Eligibility Center reviews (Hosick, 2010). These vast differences lead to many problems for universities such as international student-athletes who have violated the rules of amateurism as well as international sports agents pursing domestic student-athletes. For example, statistics gathered by the NCAA Eligibility Center show that nearly $90 \%$ of the violations of amateurism that occur are committed by international student-athletes (Hosick, 2010). A common reason for the high rates of amateur violations is due to the athletic development academies and their popularity outside of the United States. These programs allow amateur athletes to train, practice and play against professional athletes. Recently, the NCAA enacted Proposal 2009-22 with the purpose of protecting the amateur statuses of these athletes who participated in these development programs (Heitner, 2009). However, like the previous claims made against the NCAA, this only seems to hurt the student-athlete (Thamel, 2010).

The first sign of similar development programs in the United States can be seen with the United States Soccer Federation (USSF) and the creation of its own developmental program to help improve the soccer skills of American athletes. With potential success on the horizon and the growth of additional soccer academies, it is possible that other sports such as the NBA will take advantage of what Proposal 2009-22 allows (Heitner, 2009). Rachel Newman-Baker, former director of Agent, Gambling and Amateurism Activities for the NCAA, and agent Rick Smith also acknowledged recently that sports like golf and tennis in addition to men's and 
women's basketball and soccer also generate a lot of attention from international agents because the student-athletes are viewed as commodities for their business; eligibility is not their concern (Newman-Baker \& Smith, 2011).

\section{Federal and State Regulations}

In 2000, the Uniform Athlete Agents Act (UAAA) was created by the National Conference of Commissioners on Uniform State Laws (Epstein \& Niland, 2009; Neiman, 2007). The UAAA was created to provide a national standard for sports agents and student-athlete interaction in which each state could choose to enact ("National Collegiate," n.d.). The main purpose of the UAAA was to create a basic set of regulations that could protect universities and their financial investments involving student-athlete scholarships (Epstein, \& Niland, 2009; Heitner, 2010). Another function of the UAAA centered on the protection of student-athletes through education about the sports agent selection process. The first component of the UAAA pertains to sufficient information disclosure by the agent to prospective student-athletes. This provides the student-athletes and others involved a better understanding of the potential agent ("National Collegiate," n.d.).

An additional section of the act further states that if a student-athlete signs a contract before his or her eligibility has expired, then the university must be informed. The UAAA also grants the Secretary of State the authority to monitor student-athlete and agent compliance by obtaining the required information for the specific state. According to the UAAA, sports agents must be registered in a state to have any type of correspondence with student-athletes who are university students in that same state (Heitner, 2010). This specific rule creates a network to regulate the actions of agents. For example, in 2006, an Alabama registered agent, Charles Taplin, attempted to pursue student-athletes in Louisiana at Louisiana State University (LSU). Due to the fact that he was not a registered agent in Louisiana; he was arrested for violating the rules of the UAAA (Heitner, 2010). Finally, the statute has an established list of penalties that may be pursued by the state in which the violations occur. The list of penalties includes criminal, civil and administrative punishments.

The UAAA appropriately addressed major areas of concern for the studentathletes, yet, this is only effective for the 43 states and territories which have taken the necessary actions to enact the laws (Cassidy, 2013; Nocera, 2013; "Schools Push," 2013). Further, research indicates that many states associated with the UAAA also likely reduced their focus on the student-athlete protection issues. For example, states like Georgia and Delaware have eliminated the regulatory and oversight boards designated to monitor agent and student-athlete interaction while Colorado removed a state law regarding the same situation (Zagier, 2010b). To overcome the lack of state responsibility, a federal level statute was also introduced in 2004 . The Sports Agent Responsibility and Trust Act (SPARTA) prohibited the exchange of items or benefits for services between an agent and student-athlete. It also prohibits any type of contractual agreement between an agent and student-athlete before the student-athlete has completed his or her eligibility (Willenbacher, 2004). This includes any kind of oral contract or paperwork guaranteeing a contract at a later date. Included in the regulatory design of SPARTA is a list of duties that sports agents must fulfill when interacting with student-athletes. 
The first required duty of the sports agent is that the agent must be truthful with student-athletes. Another responsibility of sports agents, according to SPARTA, is the duty of disclosure. Student-athletes must be fully and accurately informed about all of the potential risks associated with the sports agent interaction. The final duty as described by SPARTA is the obligation to avoid exchanging any types of benefits or valuables with prospective student-athletes (Heitner, 2010). Although this federal act was created to serve as a net for states not protected by the UAAA, it has proven to be equally ineffective. The Federal Trade Commission, which has oversight in these issues, explains that the SPARTA board of regulations has received very few complaints during its existence and, as somewhat expected, taken no enforcement actions throughout its history (Epstein \& Niland, 2009; Zagier, 2010b).

After only a decade of existence among the federal level statutes, the efficiency and effectiveness of the UAAA and SPARTA have not provided much support for the states and their associated universities. Reports show that despite sports agent laws existing in over 40 states and territories, less than half of these states have ever withdrawn a license or enforced a penalty of any kind to unethical agents. Since 2006, the State of Florida received at least 17 complaints regarding sport agents but only two have led to the fining or punishment of an agent (Carter, 2010). The first case in the United States in which a sports agent has been charged criminally for breaking agent-related state laws occurred in North Carolina following the UNC scandal involving Greg Little and Robert Quinn (Champion Pro Consulting Group, Inc. v. Impact Sports Football, LLC, 2013; Nocera, 2013; Upchurch, 2013).

The most substantive example of an individual state which has taken corrective action is Texas. Within two years, the state made rulings on 31 cases which resulted in over $\$ 17,000$ in fines (Zagier, 2010b). While this may sound effective, $\$ 550$ per disciplinary action may not be enough to deter unethical agents from illegally pursuing the NCAA's top student-athletes, particularly when they are willing to invest thousands of dollars to establish a potential relationship and access to other athletes as well. This lack of federal and state enforcement demonstrates that sports agents taking advantage of student-athletes and universities may be a low priority (Cassidy, 2013; Getlin, 2012; Nocera, 2013).

Unfortunately, it appears supervision of the student-athlete and agent relationship might be a low priority for the NCAA as well (Fowler, 2013). The fact that the NCAA does not have the authority to discipline sports agents affecting its member universities and their student-athletes further complicates the enforcement of sports agent regulations. According to the NCAA, the only groups capable of regulating sports agents and their associates are the committed state agency regulatory bodies and the specific player associations. Despite being two of the most affected components of unethical sports agents' actions, student-athletes and their universities currently have no authority regarding sports agency (Newman-Baker, 2010). Another problem with the NCAA involves the policy of sports agent interaction compared with the recommendations available through university professional sports counseling panels (Epstein \& Niland, 2009; Fluhr, 1999). Despite the potential for biased motivations of university employees of the counseling groups, this situation also removes professional sport agents with legitimate knowledge and experience. This regulation can be considered a major reason for the unmonitored interaction between sport agents and student athletes that is currently occurring throughout the industry (Epstein \& Niland, 2009; Fluhr, 1999). 
The process of relationship building, and eventually contract signing, between a sports agent and a student-athlete largely occurs outside of the university and NCAA regulated environment (Dohrmann, 2010; Pogge \& Agnone, 2013). Andrew Brandt, a former agent, stated that sports agents and student-athletes need to establish a relationship before entering into an agreement with each other and certain players are going to sign with whoever they want. Brandt further stated that there are more ways to get clients in football, as oppose to other sports, and football has always been seen as being more accessible of a sport for agents (Fowler, 2013). In the nine page memorandum coauthored by Paul Pogge, Pogge stressed the importance of universities being informed of agents getting student-athletes to enter into agreements with them by recommending a $\$ 50,000$ fine for not notifying the university agreement within 72 hours (Pogge \& Agnone, 2013). This accountability and authority could be improved through a national organization designed to oversee the circumstances and the acceptance of other solutions centered on university campuses (e.g., Agent Days).

\section{Methods}

For this investigation, athletic departments from all 125 Division I-Football Bowl Subdivision (FBS) NCAA universities were contacted. Each university's athletic department staff directory, made available online, was used to provide point of contact information. Senior member of compliance and the director of football operations (or similarly titled position) in each university's athletic department were contacted. In a few cases, one of the two positions was listed on the directory as vacant. Two waves of emails were distributed to the aforementioned contacts. Within, the emails briefly described who we are, our interests, and what information we were interested in. The specific information we requested centered on if: a) the universities supplied student-athletes with documents or presentations regarding sports agents; b) the documents/presentations which are supplied to the student-athletes could be sent to us; c) the universities support an agent day for their student-athletes; and d) any sports other than football receive documents/ presentations regarding agents.

We received responses from 16 of the 125 schools solicited during the first wave of emails. The second wave of emails generated additional responses from another four universities for a total of 20 responses and a response rate of $16 \%$. Another nine universities directed the researchers to Cornerstone Sports Consulting, a popular sports consulting firm that provides agent-related resources for studentathlete football players. The addition of these institutions resulted in a total of 29 $(23.2 \%)$ of the 125 Division-1 FBS universities to be included in this study.

To control for nonresponse error, we followed the methods proposed by Miller and Smith (1983). According to Miller and Smith, we assumed late respondents to be similar or the same as nonrespondents. For this study, late respondents $(n=4)$ were defined as those who replied to our inquiry after the follow-up e-mail wave. On variables of interest to this study, chi-square tests (for categorical data) and independent sample $t$ tests (for continuous data) were determined to discover if 
there was a statistical difference between the means of early and late respondents. The results of that showed no significant difference on all variables of interest and confidence in our conclusion that nonrespondents were not different from the respondents.

\section{Results}

Of the 29 universities accounted for in this study, ten belong to the Southeastern Conference (SEC), five belong to the Big Ten Conference, three belong to the Big 12 Conference, two belong to the Atlantic Coast Conference (ACC), two belong to the Sun Belt Conference, one belongs to the Pacific-12 Conference (PAC-12), one belongs to Conference USA, one belongs to the Mid-American Conference (MAC), and two are independents. About $70 \%$ of SEC schools are accounted for in this study, which is the conference that produces the most football players in the NFL draft. For example, in the 2013 NFL draft, the SEC produced approximately onefourth of the athletes selected with 63 (Smith, 2013) as well as additional athletes from the SEC who signed with NFL teams after the draft. Though football is the largest team sport in terms of players on rosters, both in college and professional leagues, the SEC also produces numerous professional athletes in sports such as baseball, basketball, tennis, and golf. In addition, other peer conferences such as the ACC, Big 10, Big 12, and PAC-12 are similarly recognized as possessing elite athletics programs (Hollins, 2013) and contributed another 35\% of the member institutions accounted for in this sample.

Of the schools that responded to our emails, $60 \%$ provided some form of document or presentation to their student-athletes regarding sports agents, $25 \%$ admitted to providing no documents or presentations to their student athletes regarding sports agents, and $15 \%$ did not clearly indicate whether documentation or presentations were provided to student-athletes regarding sports agents. We received documentation and presentations from half of the schools in the sample that reportedly provide materials to student-athletes regarding agents. Two schools provided unsolicited information about providing parents educational materials regarding sports agents. In response to whether the schools have an Agent Day program, 15\% of respondents reported hosting an Agent Day for their student-athletes, 75\% of respondents reported an absence of an Agent Day on their campuses, and 10\% of respondents provided responses that did not clearly indicate whether they have an Agent Day. In addition, four schools reported the absence of an Agent Day program on their campuses provided the unsolicited information of being in favor of or currently considering an agent day program. Of the 12 schools that reportedly distribute documents or presentations to their student-athletes, five of them provided no evidence of distributing materials to sports other than football. Again, nine of the schools in the sample used Cornerstone Sports Consulting which only provides support for student-athletes who play football. One of the respondents who used the services of Cornerstone Sports Consulting stated that they do not provide any documents or presentations to student-athletes and solely rely on Cornerstone Sports Consulting for sports agent education. 


\section{Discussion}

Cornerstone Sports Consulting has at least seven SEC universities as clients which may be why so few SEC universities developed their own agent-related documents or presentations for their student athletes. Further, Cornerstone Sports Consulting provides services for student-athletes who are pursuing a career in the NFL. Among the schools that did provide us with documents and presentations, most athletic departments do not seem to be too different in the way that they orient their materials (if not all) toward football student-athletes. Though most schools that responded to the question about which sports they provide agent-related material to do not limit agent information to only football players, the documents and presentations they provide are mainly geared toward football players. This could prove to be detrimental to student-athletes of sports other than football if they are not being provided with the requisite information for establishing relationships with sports agents. The NCAA has attempted and acknowledged as such through a series of events and case studies they created to help inform universities and their studentathletes ("National Collegiate," 2010e). For example, one common scenario offered by the NCAA suggests that universities must be aware of concerns the interaction potential student-athletes have with sports agents before joining a university. In the international sports industry, many potential athletes are solicited between the ages of 12 and 16. Thus, if the athletes engage in contact and receive benefits from sports agents, their amateurism will be voided.

Improving student-athletes' knowledge about sports agent relationships may involve a more in depth study of the role of sports agent. Detailed explanations of the rules that exist and the benefits of following these rules are key for studentathletes as well as how student-athletes have been manipulated in the past (e.g., taken advantage of financially). These explanations should not only be provided by universities and third party consulting firms, but could be incorporated within professional sports counseling panels and mandatory NCAA programs. Sports counseling panels contain members who are not associated with the student-athlete before this process to reduce biased influences. The main responsibility of these panels is to provide the most appropriate advice to student-athletes in terms of the student's professional career (Newman-Baker, 2010; Newman-Baker \& Smith, 2011).

Collective accountability from all parties could greatly improve the current situation which is hurting amateur athletics. We advocate, challenge and encourage other capable programs to follow in the steps the universities who have successfully implemented Agent Day programs and provide relevant information to studentathletes from all sports. The education and accountability provided by these types of favorable environments for the student-athletes could be a major factor in improving the current issues with the sports agent industry. Education and cooperation from all parties are vital to the success and protection of student-athletes, universities, and ethical sports agents.

\section{Solving Problems Through Cooperative Education and Protection of Whistle Blowers}

The current regulations for agents have proven to be ineffective at punishing violators (Pogge \& Agnone, 2013; "Report," 2010; Zagier, 2010b). The lack of continuity and uniformity among the current regulations has been a major contributor 
to this problem. One favorable action includes the improvement of informational resources available to the student-athlete in the sports agent interaction process. Cooperative networking between all parties would be a vital part to this process. Another idea that could be a positive solution would involve required attendance at informational programs that educate student-athletes about their future dealings with prospective sport and entertainment agents.

The first and most reasonable approach to the sports agent situation should be the improved education for all parties involved. Student-athletes and their families often do not have the requisite information regarding agents, benefits, relationships, and consequences to make sound decisions (Fowler, 2013; Pogge \& Agnone, 2013). Combining the knowledge and experience of the NCAA, agents, universities, professional players associations, coaches and states could be a movement in the right directions for helping student-athletes ("National Collegiate," 2010c). The NCAA provides guidelines for agents and student-athletes, communications to student-athletes through letters with detailed rules and situations ("National Collegiate," 2010f). The NCAA also provides specific contact information for the proper government officials in each of the 43 states and territories that have passed and support the UAAA ("National Collegiate," 2010g). Some major universities currently support this educational stance through the use of Agents Days and the variety of activities associated with these programs.

Mixed feelings about Agent Day programs seem to exist among the respondent athletic departments. Some offer Agent Day programs and are very satisfied with them, others do not have them but are interested in the possibility of implementing an Agent Day program in the near future. One respondent stated that Agent Day programs are a waste of resources due in part by the fact that established sports agents rarely attend. Perhaps the third party route is beneficial for seeking established sports agents, however, it may result in a university losing a degree of access to oversee relationships between sports agents and their student-athletes. UNC created an in-house program as a result of previous infractions created in part by the unethical actions of unscrupulous agents. Overall, it seems that the trend toward Agent Day programs, whether outsourced by a third party consulting firm or implemented by the university, is growing.

The Ohio State University (OSU) provides a variety of services for studentathletes with professional sports interest. According to the Professional Sports Counseling Panel of The Ohio State University, Agent Days are opportunities to inform student-athletes about their future in a professional sports industry (Ohio State, 2009). Activities included in this opportunity include workshops, conferences, consulting advice and information from a professional sport resource center. The school manages Agent Days as an actual day on its campus where credible and registered agents, advisers and other information providers are invited to participate (Ohio State, 2009). Interestingly, Big 12 commissioner, Dan Beebe, supports such action between a school, student-athletes, and agents and argued it is critical for the school to help set-up and manage these meetings ("NCAA Studying," 2010). Within, Beebe and Ohio State argued this could encourage the agent and studentathlete interaction to occur through the regulation of the universities rather than on a street corner and thus positively promote the actions of ethical agents and players.

It was also noted that these types of informational programs offered by universities can have a variety of benefits. One major consideration is the amount of pressure removed from the student-athlete. By offering these Agent Day programs, 
student-athletes are introduced to multiple agents and other professionals in a controlled environment that promotes ethical behavior. These programs further introduce the student-athletes and their families to a wealth of information in a situation where truthful as well as thorough answers are provided. For example, survey results taken from the OSU Agent Day evaluation show that $92 \%$ of participants from previous Agent Days felt the information was useful and complete and $96 \%$ thought the overall experience was an excellent tool (Ohio State, 2009).

The experiences provided by these plans have the potential to positively affect life altering decisions made by the student-athletes. To further support these programs universities should be as thorough as possible. As an example, to attend the Agent Day program managed by OSU, agents must provide details regarding their players' associations registrations, state-specific registration information, employment records, educational backgrounds, professional services offered, a compliance background check and any other normal certifications (Ohio State, 2009). Some universities require two copies of all correspondence between their student-athletes and agents ("Solving the Problem," 2010). This range of information provides universities and their student-athletes the ability and opportunity to remain in compliance while also allowing their student-athletes greater opportunities to receive advice from agents. It also allows agents to communicate their vision and capabilities to student-athletes regarding their potential relationships and the benefits they could provide.

Finally, as more student-athletes and universities are publically punished for improper relationships with sports agents, the level of fear for this scrutiny has forced unethical and illegal actions further into the dark (Newman-Baker \& Smith, 2011). Student-athletes face a variety of pressures and unknowingly become too entrenched into negative situations. Universities must be responsible for their student-athletes but the risk of a devastating negative reputation that is associated with agent scandals is hard to overcome. The NCAA encourages student-athletes to inform their universities' compliance offices of all contact they have with potential agents ("National Collegiate", 2010d). This sharing of information, however, does not protect the student-athlete from ineligibility if they have made any mistakes at all. As a result, there is no current incentive for student-athletes to take these types of steps.

The student-athlete knows more about the negatives of agency than any other party involved. They have the information needed to start making changes in amateur athletics but with the penalties they face, have little incentive to come forward. For example, Oklahoma coach Bob Stoops believes that the best way to rectify the current agent situation would be to give absolution for student-athletes who accurately report unethical agents (Zagier, 2010a). Opening this opportunity and giving the student-athlete some power could truly influence the freedom agents have in offering improper benefits. The maturity of the student-athlete would be tested but could prove to be an equally valuable lesson in their development as a professional and as a person. The same approach could be effective if taken with universities. Providing these schools with both protection and incentives to assist in policing this problem would be beneficial to all parties. Due the difficulties of policing relationships between agents and student-athletes, the NCAA should not only encourage whistle-blowers but should protect them (Trister, 2010). The world of collegiate athletics is becoming more fragile as more unethical interactions 
between agent and student-athletes occur each day. To reverse this downfall, actions need to be taken before things become uncontrollable. We recommend improvement can occur if the current regulations in place are enforced, evaluated and possibly redesigned. Cooperation through all parties must also emerge to achieve any change. Education programs for student-athletes under controlled supervision should also occur and the protection of whistle blowers must be supported.

\section{References}

2014. MLS SuperDraft tracker. (n.d.). MLSsoccer.com. Retrieved from http://www.mlssoccer.com/superdraft/2014/tracker

Alabama's D.J. Fluker, Luther Davis among 5 SEC players receiving payouts during career: Report. (2013, September 11). Retrieved from http://www.huffingtonpost. com/2013/09/11/alabama-fluker-davis-agents-texts-benefits_n_3909852.html

Bechta, J. (2009, June 19). Cracking the agent business. Retrieved from http://www.national. footballpost.com/Cracking-the-agent-business.html

Carter, A. (2010, November 4). College football agent problem rages on more than 15 years after Foot Locker, Orlando Sentinel, Retrieved from: http://blogs.orlandosentinel.com/ sports_college_fsu/2010/11/college-football-agent-problem-rages-on-more-than15-years-after-foot-locker.html

Cassidy, R. (2013). Proposed amendments to the Uniform Athlete Agents Act attract attention in Chicago. On Lawyering. Retrieved from http://onlawyering.com/

Champion Pro Consulting Group, Inc. v. Impact Sports Football, LLC, No. 1: 12CV27 (M.D.N.C. Sept. 30, 2013).

Convention. (n.d.). Retrieved from http://www.ncaa.org/about/resources/events/convention

Couch, B. (2000). How agent competition and corruption affect sports and the athlete-agent relationship and what can be done to control it. Seton Hall Journal of Sport Law, 10, 111-137.

Davis, T. (2006). Regulating the athlete-agent industry: intended and unintended consequences. Willamette Law Review, 42, 781-818.

Deveney, S. (2006). It's the big time. Sporting News, 230(26), Retrieved from http:// http:// www.sportingnews.com/

Dohrmann, G. (2010, October 18). Confessions of an agent. Retrieved from http://sportsillustrated.cnn.com/2010/magazine/10/12/agent/index.html

Epstein, A., \& Niland, B. (2009). Sport agent litigation and the regulatory environment. Atlantic Law Journal, 11(36), 36-71.

Evans, S. (2010). Sports agents: ethical representatives or only aggressive adversaries? Villanova Sports and Entertainment Law Journal, 17, 91-133.

Florio, M. (2012). Vince Young suing former agent, financial adviser. Pro Football Talk. Retrieved from http://profootballtalk.nbcsports.com/

Fluhr, P.N., Jr. (1999). The regulation of sports agents and the quest for uniformity. Sports Lawyer Journal, 6, 1-26.

Forde, P. (2010, July 30). Cooperation key to solving agent issue. Retrieved from http:// sports.espn.go.com/ncf/columns/story?columnist=forde_pat\&id $=5422508$

Fowler, J. (2013). Clinton-Dix tale shows problems in player-agent relationship. CBS Sports. Retrieved from http://www.cbssports.com/

Getlin, R. (2012). Lawsuit: rams DE Robert Quinn accused of defrauding former agent of $\$ 300,000$. Yahoo! Sports. Retrieved from http://sports.yahoo.com/

Getlin, R., \& Cole, J. (2013). Terrell Owens suing financial adviser. Yahoo! Sports. Retrieved from http://sports.yahoo.com/ 
Heitner, D. (2009 October 26). In-depth discussion about NCAA proposal No. 2009-22, Sport Agent Blog. Retrieved from http://sportsagentblog.com/2009/10/26/in-depthdiscussion-about-ncaa-proposal-no-2009-22/

Heitner, D. (2010, October 15). It's time to seize the day. Retrieved from http://www.sportsagentblog.com/2010/10/15/its-time-to-seize-the-day/

Hollins, A. (2013). Somethings got to give, NCAA. Insiights. Retrieved from http://insiights.com

Hosick, M. (2010). International prospective student-athletes pose challenges. Retrieved from: http://www.ncaa.org/

Indianapolis, IN National Collegiate Athletic Association. Retrieved from: http://www. ncaa.org/

Isch, J. (2010, July 29). Statement from NCAA Interim President Jim Isch on agents issues.

Leung, B.J. (2013). Littlepage one of 77 supporters of stronger sports agent laws. SB Nation. Retrieved from http://www.sbnation.com/

Miller, L.E., \& Smith, K. (1983). Handling non-response issues. Journal of Extension, 21, $45-50$.

Minnis ineligible until April (2011, March 24). Retrieved from: http://www.goshockers.com/

$M L B$ draft history. (n.d.). MLB.com: The official site of Major League Baseball. Retrieved from http://mlb.mlb.com/mlb/history/draft/

Mullen, L. (2010, November 15). Financial advisers face lawsuits from NFL players. Sports Business Journal. Retrieved from http://www.sportsbusinessdaily.com.

National Collegiate Athletic Association. (n. d.) Retrieved from: http://www.ncaa.org/

National Collegiate Athletic Association. (n.d.). Need for and benefits of the Uniform Athlete Agents Act (UAAA). Retrieved from http://www.ncaa.org/

National Collegiate Athletic Association. (2010a, July 10). University of Southern California public infractions report. Indianapolis, IN: National Collegiate Athletic Association.

National Collegiate Athletic Association. (2010b, July 29). Overview of NCAA bylaws governing athlete agents. Retrieved from http://www.ncaa.org/

National Collegiate Athletic Association. (2010c, July 29). Guidelines for agents. Retrieved from http://www.ncaa.org/

National Collegiate Athletic Association. (2010d, October 11). UNC's Little and Quinn ruled permanently ineligible. Retrieved from: http://www.ncaa.org/

National Collegiate Athletic Association. (2010e, July 29). Student-athlete case studies. Retrieved from http://www.ncaa.org/

National Collegiate Athletic Association. (2010f, July 30). Example letter sent to basketball student-athletes. Retrieved from http://www.ncaa.org/

National Collegiate Athletic Association. (2010g, July 29). Contact information for states that passes the Uniform Agents Act. Retrieved from http://www.ncaa.org/

National Collegiate Athletic Association. (2011, January 14). Division I Council begins study of agent issue. Retrieved from http://www.ncaa.org/

National Football League Players Association. (2006, March 6). NFL collective bargaining agreement 2006-2012. Retrieved from: http://images.nflplayers.com/mediaResources/ files/PDFs/General/NFL\%20COLLECTIVE\%20BARGAINING\%20AGREEMENT\%202006\%20-\%202012.pdf

NCAA studying athlete/agent interaction. (2010, July 30). Retrieved from http://sports.espn. o.com/ncaa/news/story?id=5423136

Neiman, M. (2007). Fair game; ethical considerations in negotiation by sports agents. Texas. Review of Entertainment and Sports Law, 9, 123-140.

Newman-Baker, R. (2010, July 29). Gambling and amateurism activities. Indianapolis, IN:

Newman-Baker, R., \& Smith, R. (2011, January). Continuing eligibility and amateurism. 2011 NCAA Convention Association-Wide Educational Session. Symposium conducted at the meeting of the NCAA Convention, Atlanta.

NFL draft history - by school. (n.d.). National Football League. Retrieved from http://www. nfl.com/draft/history/fulldraft?type=school 
Nocera, J. (2013). The North Carolina five. The New York Times. Retrieved from http:// www.nytimes.com/

The Ohio State University Athletic Department. (2009). Ohio State Agent Day. Columbus, $\mathrm{OH}$ : The Ohio State University.

O'Neil, D. (2010, July 30). Will agents get an invite to the table? Retrieved from http://sports. espn.go.com/ncb/columns/story?columnist=oneil_dana\&id=5421033

Pogge, P., \& Agnone, T. (2013, October 10). Recommendations for the Amended Uniform Athlete Agents Act Drafting Committee. [Memorandum to Amended Uniform Athlete Agents Act Drafting Committee]. Retrieved from http://www.uniformlaws.org/shared/ docs/athlete_agents/2013oct10_AUAAA_Memo_Pogge\%20and\%20Agnone.pdf

Probability of competing beyond high school. (2013, September). NCAA. Retrieved from http://www.ncaa.org/about/resources/research/probability-competing-beyond-highschool

Report: State agent laws unenforced. (2010, August 17). Retrieved from http://sports.espn. go.com/ncaa/news/story?id=5470067

Riepenhoff, J., \& Wagner, M. (2010). Sports agents placed on notice. Columbus Dispatch, Retrieved from http://www.dispatch.com/

Robinson, C., \& Fischer, B. (2010, August 9). Coach-agent ties probed. Rivals, Retrieved from: http://rivals.yahoo.com/ncaa/football/news?slug=ys-agentcoach080910

Saban compares agents to a 'pimp'. (2010, July 22). Retrieved from http://sports.espn. go.com/ncf/news/story?id=5399270

Schools push for stronger agent laws. (2013, October 11). Retrieved from http://espn.go.com/ college-football/story/_id/9809766/officials-65-schools-want-stronger-agent-laws

Seifried, C.S. (2009). What Division I men's college basketball recruiting tactics tell us about the college athlete choice of institution process: A brand elimination approach. Applied Research in Coaching \& Athletics Annual., 24, 85-124.

Smith, M.D. (2013). With 63 draft picks, SEC produces a quarter of the NFL's talent. Pro Football Talk. Retrieved from http://profootballtalk.nbcsports.com/

Solomon, J. (2013). Amnesty to colleges and athletes for exposing shady agents? 'What's the NCAA say?'. The Huntsville Times. Retrieved from http://www.al.com/

Solving the problem: sports agents in college sports. (2010, September 2). Retrieved from http://www.opposingviews.com/i/solving-the-problem-sports-agents-in-college-sports

Statement: Joint effort to tackle football agent issues continues (2010, October). Meeting conducted at the National Collegiate Athletic Association, Indianapolis. Retrieved from: http://www.ncaa.org/

Thamel, P. (2010, September 7). Turkish team says it paid a Kentucky recruit. New York Times. Retrieved from http://www.nytimes.com/2010/09/08/sports/ ncaabasketball/08basketball.html

Trister, N. (2010, July 20). Schools, agents on notice amid NCAA investigations. Boston. com. Retrieved from http://www.boston.com/

United States of America v. Walters 997 F.2d 1219 (7th Cir. 1993).

Upchurch, K. (2013). Trials of sports agents, ex-UNC professor set for 2014. The HeraldSun. Retrieved from http://www.heraldsun.com/

Willenbacher, E. (2004). Regulating sports agents: Why current federal and state efforts do not deter the unscrupulous athlete-agent and how a national licensing system may cure the problem. St. John's Law Review, 78, 1225-1256.

Year-by-year lottery picks. (n.d.). NBA.com. Retrieved from http://www.nba.com/history/ lottery_picks.html

Zagier, A. (2010a, September 2). Agent oversight continues to vex college sports. Huffington Post, Retrieved from http://www.huffingtonpost.com/2010/09/02/agent-oversightcontinues_n_703143.html

Zagier, A. (2010b, August 17). Laws on sports agents rarely enforced. Huffington Post. Retrieved from http://www.huffingtonpost.com/ 